\title{
The effect of perceived educational support, self-efficacy and planned behavior predictors on entrepreneurial intention of Ho Chi Minh City University students
}

\author{
Nguyen Ngoc Duy Phuong ${ }^{1 *}$, Quang Ngoc Thuy Van ${ }^{1}$, Nguyen Duc Dung ${ }^{2}$ \\ ${ }^{1}$ School of Business, International University, Vietnam National University Ho Chi Minh City, Vietnam \\ ${ }^{2}$ VinTech City, Vietnam \\ *Corresponding author: nndphuong@hcmiu.edu.vn
}

\begin{tabular}{ll}
\hline \multicolumn{1}{c}{ ARTICLE INFO } & \multicolumn{1}{c}{ ABSTRACT } \\
\hline $\begin{array}{l}\text { DOI:10.46223/HCMCOUJS. } \\
\text { econ.en.10.1.226.2020 }\end{array}$ & $\begin{array}{l}\text { The research attempts to quantify the significance of perceived } \\
\text { education support, self-efficacy, and the theory of planned behavior } \\
\text { in predicting the entrepreneurial intention among undergraduate } \\
\text { students in Ho Chi Minh City (HCMC). The paper employs a 28- } \\
\text { item questionnaire to acquire information on undergraduate } \\
\text { Received: September } 16^{\text {th }}, 2019 \\
\text { Revised: November } 24^{\text {th }}, 2019\end{array}$ \\
$\begin{array}{l}\text { Accepted: April } 20^{\text {th }}, 2020 \\
\text { demographics and six variables based on the five-point Likert scale. } \\
\text { SmartPLS version 3.0 was applied to analyze statistical data } \\
\text { collecting from 312 students in three selected universities in Ho Chi } \\
\text { Minh City. The findings indicate that perceived education support } \\
\text { and two elements of theory planned behavior, specifically, attitude } \\
\text { towards entrepreneurship and perceived behavioral control } \\
\text { positively and significantly affect entrepreneurial intention. }\end{array}$ \\
$\begin{array}{l}\text { Keywords: } \\
\text { entrepreneurial intention, self- } \\
\text { efficacy, perceived education } \\
\text { support, students }\end{array}$ & $\begin{array}{l}\text { on attitude towards entrepreneurship. Overall, the paper suggests } \\
\text { practical implications in increasing entrepreneurship intention } \\
\text { toward undergraduates. }\end{array}$
\end{tabular}

\section{Introduction}

There has been a positively tight connection between entrepreneurial activities and economic development. In the first half of the twentieth century, Schumpeter highlighted the crucial value of entrepreneurship to economic growth (Śledzik, 2013). Acs and Szerb (2009) confirmed its significant influence in specific figures through researches in many countries. Realizing the significance, Vietnamese government has promulgated an investment policy regarding FDI to push up entrepreneurial motivation. Consequently, Ho Chi Minh City (HCMC) has currently been valued as one of the most significant economic development regions in Vietnam with many attractive projects valued a ton of dollars. According to General Statistics Office, HCMC appealed the highest portion of FDI nearly two decades, from 1988 to 2006, which created a multi-cultural dynamic environment for young entrepreneurs to authenticate their talent and fulfill their dream (UNCTAD, 2008). Also, the young seemed to have the intention to be selfemployed entrepreneurs (Gielnik, 2018). Specifically, the young generation with the age range 18 to 34 is more likely to become an entrepreneur than the older people from 35 to 64 (Global Entrepreneurship Monitor, 2014). Their purpose is to gain financial independence as well as accelerate to national economic development. The typical study in India dedicated to the source of mankind's knowledge that entrepreneurs succeed at a relatively young age (Sinha, 1996). According to the World Bank statistics, Vietnam experienced a big jump in ease of doing business 
ranking, from 99 among 190 nations in 2013 to 69 in 2018, which is considered a potential market in the eye of the investors. However, the unemployment rate of the young generation aging from 15 to 24 is relatively high, increasing from $7.07 \%$ in January to $7.29 \%$ in September in 2018 (General Statistics Office of Vietnam, 2018). Therefore, it is extremely urgent to identify factors influencing entrepreneurial intention to lower the young unemployment rate.

People are not interested in engaging in entrepreneurial initiatives when they have limited education (GEM, 2001). Many universities in Vietnam have focused on the business segment providing students with the fundamental and necessary knowledge of entrepreneurship. Questions of how effectively these courses shape the intention to start-up among university students, however, remain since insufficient studies investigate the effect of education support on the tendency to create venture in Vietnam. Thus, the paper aims to investigate the significance of perceived education support in the group of university students in HCMC with the theory of planned behavior.

\section{Literature review and hypotheses development}

\subsection{Entrepreneurial intention}

Entrepreneurial intention reflects a state of mind that individuals prefer self- employment to being employed. According to Thompson (2009), entrepreneurial intention refers to a personal belief that the individual intended to have a new enterprise established with a specific plan in the future. That point may be forthcoming, unpredictable, or even not happen since the intention may change over time. Still, the intention is a prominent forecaster of planned behavior (Bagozzi, Baumgartner \& Yi, 1989). Although not all the intentions are executed, actions are controlled by intentions (Ajzen, 1985).

The entrepreneurial intention has been an appealing framework and considerably huge phenomenon that has been extensively researched. Many previous scholars reveal the connections between individual traits and entrepreneurial intention in diverse periods and research contexts (Brandstätter, 2011; Crant, 1996; Leutner, Ahmetoglu, Akhtar, \& Chamorro-Premuzic, 2014; Nasip, Amirul, Sondoh Jr, \& Tanakinjal, 2017; Şahin, Karadag, \& Tuncer, 2019). On the other hand, Shinnar, Giacomin, and Janssen (2012) believed that the cultural environment is an issue when coming to the obstacles to form an intention to establish a venture. From a broader viewpoint, an individual's career can be influenced by the immediate personal environment and socio-cultural context (Lent, Brown, \& Hackett, 2000). Holding a different point of view, Ferreira, Raposo, Gouveia Rodrigues, Dinis, and do Paço (2012) and Munir, Jianfeng, and Ramzan (2019) applied psychology - behavioral model of factors impacting entrepreneurial intention. Generally, the frameworks have been integrated over time to provide a more comprehensive system toward entrepreneurial intention in various respects.

\subsection{Theory of planned behavior}

According to Bird (1988), it required a careful plan to form a new venture. Also, entrepreneurship has been an intentional and planned behavior. The behavior in the future can be directly predicted by behavioral intention (Ajzen, 1991). To Kautonen, van Gelderen, and Fink (2015), the remarkable impact of EI on the behavior of setting up an enterprise is verified. Several existing models basing on intention have been advanced to comprehend and forecast the behavior of the individual, depended on the Theory of Planned Behavior and Krueger- Shapero model (Schlaegel \& Koenig, 2014). the Theory of Planned Behavior is developed from the Theory of Reasoned Action to deal with volitional control (Ajzen, 1985). 
The Theory of Planned Behavior has dominated in numerous empirically study papers regarding intention to start-up so far (Munir et al., 2019; Shah \& Soomro, 2017; Zhang \& Cain, 2017). The validity and applicability of the Theory of Planned Behavior have been reasserted in diverse cultural contexts (Al-Shammari \& Waleed, 2018; Iglesias-Sánchez, Jambrino-Maldonado, Velasco, \& Kokash, 2016; Miranda, Chamorro-Mera, Rubio, \& Pérez-Mayo, 2017). However, the strength of individual tendency to form a venture leans on the national economic status. The stronger predictive power towards entrepreneurial intention in an emerging economy has been illustrated by the Theory of Planned Behavior model. Specifically, Munir, Jianfeng, and Ramzan (2019) demonstrated the differences in the impact of the Theory of Planned Behavior model on intention towards entrepreneurship between final year students in China and Pakistan. To Theory of Planned Behavior, the individual effort to create entrepreneurship has been shaped by specific antecedents, including attitude toward entrepreneurship, subjective norm, and perceived behavioral control.

\subsubsection{Attitude toward entrepreneurship}

A person can have a positive or negative attitude towards a particular behavior. This attitude is defined as an awareness of individuals about behavioral beliefs and outcome evaluations (Ajzen, 1991). When an individual perceives an increasing appeal to establishing an enterprise, the intention towards entrepreneurship increases (Krueger, Reilly, \& Carsrud, 2000).

Several prior research papers have revealed that Attitude toward Entrepreneurship (ATE) has played the most principal role in impacting individuals to start an enterprise (Ferreira et al., 2012; Miranda et al., 2017). Shah and Soomro (2017), and Zhang and Cain (2017) highlighted that ATE is positively and greatly correlated with entrepreneurial intention (EI) of students of universities in Pakistan and Southeastern USA respectively. Even though researches have been conducted in various economies and culture, the findings still indicate that ATE significantly affects EI (Trivedi, 2016; Farooq et al., 2018). Thus, the study proposes hypothesis H1 as following.

\section{H1: ATE is positively and significantly correlated with EI}

\subsubsection{Subjective norm}

It is known that subjective norm is one of the important determinants of the Theory of Planned Behavior. According to Ajzen (1991), subjective norm reflects an individual normative belief regarding an intention or behavior. In other words, it can be defined as a social influence of others, namely, family members, relatives, friends, and other important people on an individual perception towards planned behavior. Subjective norm essentially contributes to the development of individual intention to become an entrepreneur (Ajzen, 1991).

Subjective norm (SN) vitally influences the start-up intention of students at the secondary level (Ferreira et al., 2012). Shah and Soomro (2017) detected the prominent impact of SN on EI of university students. The importance of SN to EI is also found in the group of fresh graduated (Farooq et al., 2018). On the contrary, other study results showed that SN has no impact on EI (Trivedi, 2016). Iglesias-Sánchez (2016) showed that SN is not a significant influencer of EI. The inconsistent results may come from the differences in research contexts. Thus, the paper is to evaluate the influence of SN on the intention of the start-up of undergraduates in HCMC.

Since "reference people" is considered to influence the decision toward entrepreneurship (Ajzen, 2001), it is logical to set up a positive relationship between factor SN and EI. The hypothesis is suggested as following. 


\section{H2: SN is positively and significantly correlated with EI}

\subsubsection{Perceived behavioral control}

One of the crucial determinants of the Theory of Planned Behavior is perceived behavioral control. Ajzen (2002) explained that the term "perceived behavioral control" was interpreted as "perceived control over performance of behavior" to prevent misleading. To Theory of Planned Behavior, the element perceived behavioral control implies individuals' perception of their competencies to execute the planned behaviors and the control's degree over the performance of that behavior (Ajzen, 1991). In order words, this element relates to the perception of whether the planned behavior is feasible with the involvement of internal and external constraints.

With a greater perception of $\mathrm{PBC}$, individuals will have a greater intention to implement the planned behavior (Krueger et al., 2000). According to Trivedi (2016), PBC scores are found to have a positive relation with the intention to start a venture. Moreover, Alonso-Galicia, Fernández-Pérez, Rodríguez-Ariza, and Fuentes-Fuentes (2015), Iglesias-Sánchez et al. (2016), Miranda et al. (2017), and Farooq et al. (2018) contributed to the fact that a significant and positive relationship between $\mathrm{PBC}$ and the intention to have an enterprise established has existed. However, Ferreira et al. (2012), and Shah and Soomro (2017) revealed that PBC has no impact on EI among students in secondary and private universities as it is supposed to. Additionally, PBC is not an influencer of the intention to form an informal entrepreneurship in Peru (Amésquita Cubillas, Morales, \& Rees, 2018). This paper will assess the impact of PBC on the intention to pursue the entrepreneurship of university students in HCMC and suppose PBC influences on EI. Therefore, the hypothesis is proposed below.

\section{H3: PBC is positively and significantly correlated with EI}

\subsection{Self-efficacy}

Self-efficacy specifies the beliefs of individuals about their abilities to execute the planned behavior which can be created and altered by the four primary sources, including vicarious experiences, social persuasions, mastery experiences, and physiological and affective states (Bandura, 1997). High self-efficacy people perceive difficult tasks as a challenge to conquer and maintain strong engagement with their set challenging goals (Bandura, 1993). Self-efficacy has an impact on human behavior and selection (Bandura, 1986). Bandura (1993) revealed that selfefficacy is a decisive contributor to academic development in three levels.

Ajzen (2002) differentiated the term "Self-efficacy" and "Perceived behavioral control" in the study. Nonetheless, self-efficacy and perceived behavioral control have been interchangeably used in several papers (Droms \& Craciun, 2014). Hence, this paper aims to compare perceived behavioral control and self-efficacy within the context of entrepreneurship intention of HCMC undergraduate students.

Self-efficacy is one of the determinants that attract many scholars to investigate. Consequently, existing research papers have implied that self-efficacy (SE) has a great influence on the decision to pursue entrepreneurship. Bell (2019), Kristiansen and Indarti (2004), Sesen (2013) and Shahab (2018) asserted that an increase in self-efficacy will yield greater intentions to be entrepreneurs of students in diverse contexts. The research results confirm that SE has a significant effect on the EI. The hypothesis is suggested based on the results of these studies as follows. 
H4: SE is positively and significantly correlated with EI

\subsection{Perceived education support}

According to Gelard and Saleh (2011), education support at university is a crucial element that affected the entrepreneurial intention of students. Trivedi (2016) confirmed the essential of entrepreneurial education at school to form the entrepreneurship intention. Moreover, entrepreneurship education provided at institutions, schools, universities, or through postgraduate training programs was considered a vital education (Hattab, 2014).

Gelaidan and Abdullateef (2017) arrived at the result that educational support at College of Business in Malaysia has a positive correlation with the tendency to be entrepreneurs of students in diverse cultures, namely Malaysia, Chinese, Indian, and others. Furthermore, Gelard and Saleh (2011) revealed that students at Accounting Management College perceive education support as a crucial factor to develop the intention to start-up. Students in Turkey also consider PES an important determinant of deciding towards entrepreneurship (Turker \& Sonmez Selcuk, 2009). This paper will examine the influence of PES on the intention to form a venture of HCMC university students. It is supposed that PES significantly affects EI which raises a hypothesis as below.

\section{H5: PES is positively and significantly correlated with EI}

Accordingly, Athayde (2009) figured out the fact that the entrepreneurial program provided for young age students has a positive impact on their attitude towards self-employment. Another researcher that confirmed the positive correlation between education and individual attitude is Basu (2010). The result indicates that the exposure to education about entrepreneurship favorably affects attitude towards entrepreneurship of students (Basu, 2010). However, Heuer and Kolvereid (2014) proved that entrepreneurial education makes no significant contribution to explaining ATE. Indeed, the effect of PES on ATE varies among previous studies.

In this case, this paper will assert the impact of PES antecedent on venture creation of undergraduate students in HCMC with the proposed hypothesis below

H6: PES is positively and significantly correlated with ATE

\section{Research design}

Undergraduate university students in $\mathrm{HCMC}$ who currently studied at International University (IU), University of Economics HCMC (UEH), Banking University of HCMC (BUH) were invited to participate in the research. The research based on the data of students in business majors analyzes the effect of entrepreneurial education support of the entrepreneurship courses in the universities.

The theoretical model of this paper was measured by employing Partial Least Squares approaching to Structural Equation Modeling (PLS-SEM) with Smart PLS version 3.0. It consists of 2 steps to firm the conceptual framework which are assessing the measurement model and evaluating the structural model.

\subsection{Sample size}

There were 333 questionnaires directly distributed at specific universities in electronic and paper forms. For electronic form, questionnaires in Google docs form were posted on universities' pages which gathered 170 responses. Only 144 out of 163 papers allocated directly to students at selected universities and collected after fulfilling for further analysis were returned. The total 
number of responses was 314 with a relatively high response rate (94.29\%). However, 312 answers were valid due to eliminating 2 uncompleted responses.

Table 1

Demographic characteristics

\begin{tabular}{|c|c|c|c|}
\hline & $n$ & Mean & $\%$ \\
\hline \multicolumn{4}{|l|}{ Gender } \\
\hline Female & 211 & & 67.63 \\
\hline Male & 101 & & 32.37 \\
\hline Age & 312 & 21.09 & \\
\hline \multicolumn{4}{|l|}{ University } \\
\hline International University & 144 & & 46.15 \\
\hline University of Economics & 83 & & 26.60 \\
\hline Banking University & 85 & & 27.24 \\
\hline \multicolumn{4}{|l|}{ Major } \\
\hline Business Administration & 111 & & 35.58 \\
\hline International Business & 67 & & 21.47 \\
\hline Finance Banking & 47 & & 15.07 \\
\hline Accounting Finance & 43 & & 13.78 \\
\hline Marketing & 38 & & 12.18 \\
\hline Hospitality Administration & 6 & & 1.92 \\
\hline
\end{tabular}

Source: The research's data analysis

Table 1 illustrates the demographic characteristics of the participants, including gender, age, university, and major. The noticeable point in the data is that the number of female participants approximately doubles that of the male. It illustrates the fact that female students tend to enroll in business majors more than males do.

\subsection{Measurements}

The questionnaires comprise 2 distinct sections. The first one obtains demographic information of participants, including gender, age, major and current university. The second section concentrates on 28 items of 6 antecedents - ATE, PBC, SN, SE, PES, and EI, employing a 5-point Likert scale. The theory of planned behavior (ATE, PBC, and SN) was measured, based on the adapted measurement scale of Shah and Soomro (2017) from Ajzen (1991). Six items were developed to assess SE coming from De Noble, Jung, and Ehrlich (1999), and Liñán and Chen (2009) suggestions. This research applied the 3 items of Turker and Sonmez Selcuk (2009) based on the scale of Parnell, Crandall, and Menefee (1995) to measure the influence of PES among undergraduates. Accordingly, the evaluation of EI has relied on suggestions of Liñán and Chen (2009). The measuring scale was integrated from diverse papers and initially in English. To 
accurately collect the real perception of participants and avoid making them confused, the questionnaire was translated into Vietnamese with simple and clear words by the author.

\section{Findings}

\subsection{Assessment of measurement model}

To assess the measurement model, internal consistency reliability, convergent validity, and discriminant validity were explored. Firstly, every single loading of indicators in the research was inspected whether the constructs satisfy the criteria requirements of 0.7 (Hair, Hult, Ringle, \& Sartstedt, 2013). Eight items were eliminated from the scale, specifically, three items from factor PBC (PBC1, PBC2, PBC3) and SE (SE1, SE2, SE4), one item from factor PES (PES1) and SN (SN1) are removed. After revising, the outer loadings of the factors fall in the range of 0.739 to 0.937 .

\section{Table 2}

Reliability, validity results of constructs

\begin{tabular}{lccl}
\hline & CR & Cronbach's Alpha & AVE \\
\hline ATE & 0.910 & 0.876 & 0.671 \\
EI & 0.935 & 0.913 & 0.744 \\
PBC & 0.877 & 0.723 & 0.782 \\
PES & 0.862 & 0.701 & 0.759 \\
SE & 0.857 & 0.751 & 0.667 \\
SN & 0.858 & 0.750 & 0.669 \\
\hline
\end{tabular}

Source: Data analysis result of the research

In terms of assessing internal consistency reliability, Kwong and Wong (2013) suggested that the tendency of Cronbach's in PLS-SEM alpha was to provide conservative measurements. However, Hair et al. (2013) suggested that composite reliability would result in a better estimate. Therefore, both composite reliability (CR) and Cronbach's Alpha were applied to guarantee the data reliability in this study. Findings revealed that all constructs of the model have CR and Cronbach's Alpha values exceeding the requirement of 0.7 , proving the reliability of constructs. The list of reliability and validity results is shown in Table 2 .

Convergent validity of the measurement tool is estimated by Average Variance Extracted (AVE). According to Fornell and Larcker (1981), the value of AVE should be greater than 0.5. The AVE values of the constructs are all above the threshold value, ranging from 0.667 to 0.782 .

Table 3

Fornell-Larcker criterion (square root of AVE)

\begin{tabular}{lcccccc}
\hline & ATE & EI & PBC & PES & SE & SN \\
\hline ATE & 0.819 & & & & & \\
EI & 0.787 & 0.863 & & & & \\
PBC & 0.502 & 0.597 & 0.884 & & & \\
PES & 0.452 & 0.492 & 0.314 & 0.871 &
\end{tabular}




\begin{tabular}{lcccccc}
\hline & ATE & EI & PBC & PES & SE & SN \\
\hline SE & 0.569 & 0.532 & 0.526 & 0.374 & 0.817 & \\
SN & 0.492 & 0.533 & 0.593 & 0.429 & 0.485 & 0.818 \\
\hline
\end{tabular}

Source: Data analysis result of the research

Discriminant validity is verified by the Fornell-Larcker criterion and cross-loadings. The square roots of AVE values measured on the constructs surpass the correlations shared between the constructs and others. In other words, constructs are independent, presented in Table 3. In addition, cross-loading values of the observed variables in latent variables are always higher than the others, shown in Table 4. In principle, this means that the model has discriminant validity since it fits the criteria.

Table 4

Values of cross-loadings

\begin{tabular}{lcccccc}
\hline & ATE & EI & PBC & PES & SE & SN \\
\hline ATE1 & $\mathbf{0 . 8 7 1}$ & 0.716 & 0.419 & 0.377 & 0.466 & 0.459 \\
ATE2 & $\mathbf{0 . 7 3 9}$ & 0.521 & 0.325 & 0.361 & 0.308 & 0.275 \\
ATE3 & $\mathbf{0 . 8 5 2}$ & 0.671 & 0.415 & 0.379 & 0.483 & 0.413 \\
ATE4 & $\mathbf{0 . 7 7 0}$ & 0.592 & 0.428 & 0.334 & 0.517 & 0.443 \\
ATE5 & $\mathbf{0 . 8 5 7}$ & 0.701 & 0.460 & 0.399 & 0.543 & 0.412 \\
EI1 & 0.644 & $\mathbf{0 . 7 9 2}$ & 0.578 & 0.510 & 0.466 & 0.505 \\
EI2 & 0.716 & $\mathbf{0 . 9 0 6}$ & 0.507 & 0.351 & 0.439 & 0.445 \\
EI3 & 0.709 & $\mathbf{0 . 8 8 2}$ & 0.527 & 0.483 & 0.557 & 0.479 \\
EI4 & 0.680 & $\mathbf{0 . 9 2 7}$ & 0.535 & 0.425 & 0.458 & 0.485 \\
EI5 & 0.639 & $\mathbf{0 . 7 9 6}$ & 0.414 & 0.341 & 0.358 & 0.375 \\
PBC4 & 0.488 & 0.572 & $\mathbf{0 . 9 0 6}$ & 0.278 & 0.455 & 0.518 \\
PBC5 & 0.393 & 0.476 & $\mathbf{0 . 8 6 2}$ & 0.278 & 0.480 & 0.534 \\
\hline & ATE & EI & PBC & PES & SE & SN \\
\hline PES2 & 0.289 & 0.286 & 0.143 & $\mathbf{0 . 8 0 0}$ & 0.234 & 0.287 \\
PES3 & 0.465 & 0.524 & 0.357 & $\mathbf{0 . 9 3 7}$ & 0.388 & 0.434 \\
SE3 & 0.432 & 0.474 & 0.419 & 0.408 & $\mathbf{0 . 8 2 6}$ & 0.387 \\
SE5 & 0.494 & 0.428 & 0.475 & 0.252 & $\mathbf{0 . 8 4 0}$ & 0.382 \\
SE6 & 0.475 & 0.396 & 0.396 & 0.242 & $\mathbf{0 . 7 8 5}$ & 0.424 \\
SN2 & 0.347 & 0.446 & 0.430 & 0.405 & 0.367 & $\mathbf{0 . 8 2 7}$ \\
SN3 & 0.398 & 0.447 & 0.435 & 0.299 & 0.349 & $\mathbf{0 . 8 7 3}$ \\
SN4 & 0.467 & 0.414 & 0.599 & 0.349 & 0.481 & $\mathbf{0 . 7 4 8}$ \\
\hline SE & 0.45 & & \\
\hline
\end{tabular}

Source: Data analysis result of the research 


\subsection{Assessment of the structural model}

Parametric significance tests have great power when the used data set is a normal distribution. However, it is uncertain that the data set using in PLS-SEM in the research is the normal distribution. Therefore, the coefficient significance is tested by PLS-SEM relying on nonparametric bootstrapping (Hair et al., 2013). It is revealed that a nonparametric bootstrapping procedure is utilized in every sign change (Hair, Ringle, \& Sarstedt, 2011; Henseler, Ringle, \& Sinkovics, 2009). In this study, there are 312 cases and 1,000 subsamples. After running the bootstrapping procedure, $t$-values were evaluated to examine the statistical significance of the coefficient. A complete illustration of results derived from the structural model is demonstrated in Figure 1.

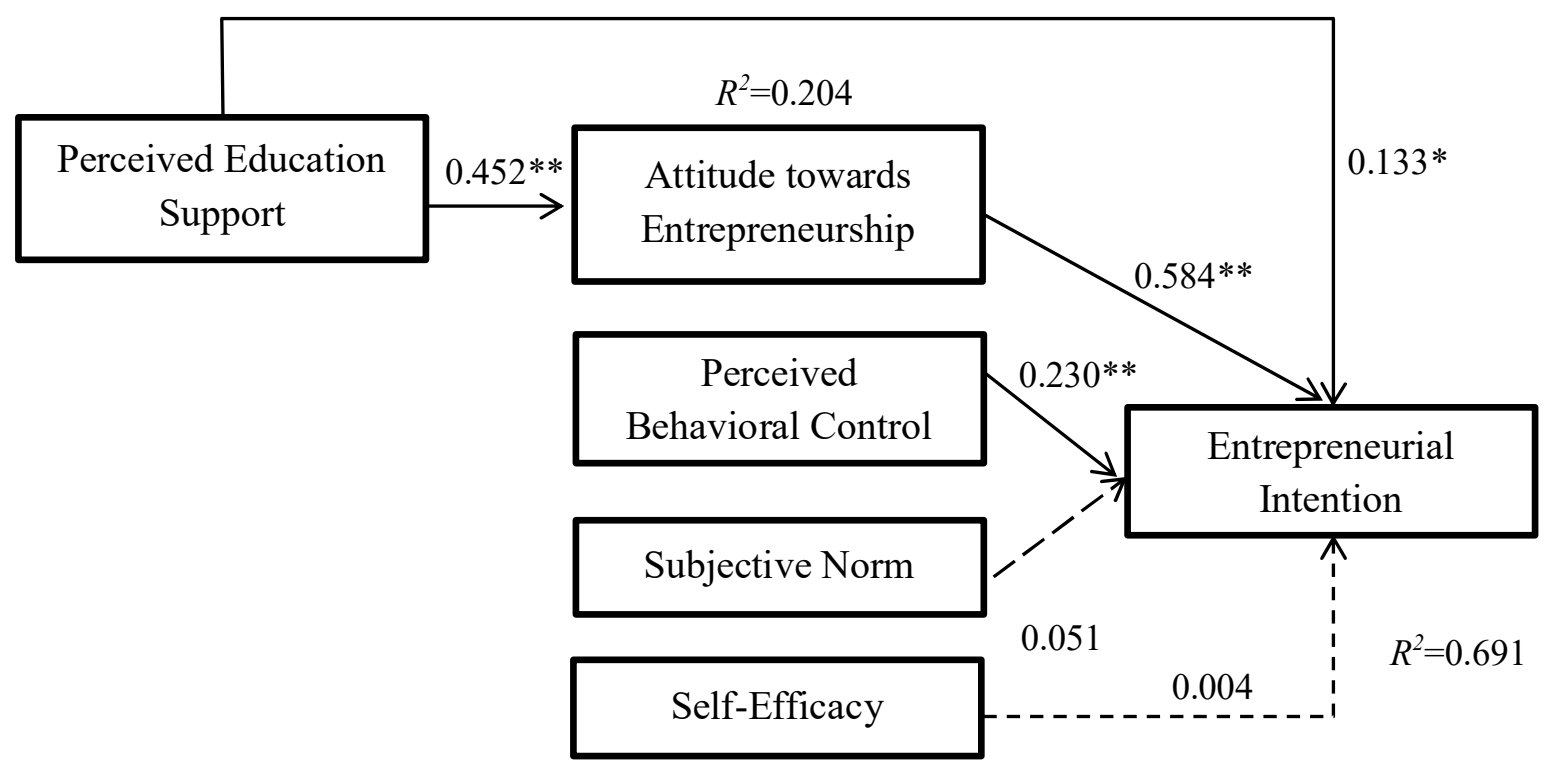

Note: ${ }^{*} p<0.01,{ }^{*} p<0.001$

Figure 1. Findings of structural model

It is seen that the $R^{2}$ value of EI is 0.691 , indicating moderate predictive accuracy. It refers to $69.1 \%$ of the variance in EI that is explained by 5 predictors, including ATE, SN, PBC, SE, and PES. Additionally, $R^{2}$ value of ATE is 0.204 , indicating the very weak predictive accuracy. It implies that the predictor PES accounted for $20.4 \%$ of the variance in EI. Besides R square value, Predictive relevance, or Q square, was advanced and considered critical to assess the predictive validity of the model (Chin, 2010; Hair, Hult, Ringle, \& Sarstedt, 2017). By running blindfolding with an omission distance of seven, $Q^{2}$ value was calculated. Findings show that $Q^{2}$ value of the structural model is 0.477 , which is above 0 implying that endogenous construct EI has relevant prediction power with all exogenous constructs in the research. Moreover, $Q^{2}$ value of ATE is 0.128; hence, ATE has predictive relevance for PES.

\section{Table 5}

Hypothesis testing

\begin{tabular}{cccccl}
\hline Hypothesis & Relationships & $\begin{array}{c}\text { Path } \\
\text { Coefficients }\end{array}$ & $\begin{array}{c}\text { T } \\
\text { Statistics }\end{array}$ & $\begin{array}{c}\text { P } \\
\text { Values }\end{array}$ & Decision \\
\hline H1 & ATE -> EI & 0.584 & 12.736 & 0.000 & Supported \\
H2 & SN -> EI & 0.051 & 1.108 & 0.268 & Not Supported
\end{tabular}




\begin{tabular}{cccccl}
\hline Hypothesis & Relationships & $\begin{array}{c}\text { Path } \\
\text { Coefficients }\end{array}$ & $\begin{array}{c}\text { T } \\
\text { Statistics }\end{array}$ & $\begin{array}{c}\text { P } \\
\text { Values }\end{array}$ & Decision \\
\hline H3 & PBC -> EI & 0.230 & 4.431 & 0.000 & Supported \\
H4 & SE -> EI & 0.004 & 0.081 & 0.936 & Not Supported \\
H5 & PES -> EI & 0.133 & 2.812 & 0.005 & Supported \\
H6 & PES -> ATE & 0.452 & 9.948 & 0.000 & Supported \\
\hline
\end{tabular}

Source: Data analysis result of the research

The finding reveals that the two antecedents of the Theory of Planned Behavior, namely, ATE $(\beta=0.584, p=0.000)$ and $\operatorname{PBC}(\beta=0.230, p=0.000)$ are verified to have positive and great impacts on the EI. On the other hand, $\mathrm{SN}(\beta=0.051, \mathrm{p}=0.268)$ has no impact on the EI. As a result, $\mathrm{H} 1$ and $\mathrm{H} 3$ are supported while $\mathrm{H} 2$ is not supported.

The result has indicated that the influence of $\mathrm{SE}(\beta=0.004, \mathrm{p}=0.936)$ on $\mathrm{EI}$ is not significant. On the contrary, PES affects EI with $\beta=0.133, p=0.005$, and ATE with $\beta=0.452, p=0.000$ in a significant and positive manner. Consequently, $\mathrm{H} 4$ is rejected while $\mathrm{H} 5$ and $\mathrm{H} 6$ are supported. Table 5 summarizes the path coefficients and hypotheses testing of the study.

\section{Discussion and conclusion}

The research focuses on determining the relative abilities of the constructs to predict entrepreneurial intention across three different universities in HCMC. In short, the study attempts to determine and evaluate the influence level of the Theory of Planned Behavior, self-efficacy, and education support at universities on the decision to join entrepreneurship. Regarding the first objective of the research identifying the antecedents of the entrepreneurial intention of undergraduates, the finding illustrates that perceived education support and two elements of theory planned behavior, specifically, attitude towards entrepreneurship and perceived behavioral control positively and significantly affect entrepreneurial intention.

Finding reveals that attitude towards entrepreneurship is the most prominent predictor in predicting entrepreneur intention. The research confirms the previous studies' findings that the attitude of the students is a principal facet of the development of entrepreneurial intention (Farooq et al., 2018; Shah \& Soomro, 2017; Trivedi, 2016; Zhang \& Cain, 2017). One of the rational reasons for this consequence is that undergraduates may have been exposed to entrepreneurship from the community and their own experiences which enhance their attitudes level towards entrepreneurship. Start-up has become a social trend that attracts the attention of the majority of people, especially the young. Many TV shows concentrating on start-up topics, such as Shark Tank, provide students with practical entrepreneurial knowledge as well as creative ideas for career creation. Besides, students may expose to entrepreneurship by taking a part-time job in their spare time.

To encourage the entrepreneurial spirit of undergraduate students, universities should place more of an emphasis on improving the degree of attitude towards entrepreneurship among undergraduates. Specifically, universities can encourage competitions and programs regarding entrepreneurship which enhance the attitude degree of a student towards entrepreneurship. Inviting guest speakers who can practically share their experiences and difficulties in establishing and operating their businesses is one of an activity that not only provides entrepreneurial knowledge for students, clears up their queries directly but also inspires them to pursue entrepreneurship. Additionally, who are founding a community for students interested in entrepreneurship is also 
essential. With the help of policymakers, students can immerse themselves in the environment where they share the same enthusiasm and increase their awareness about entrepreneurship. Besides, public policy decision-makers can offer students loans with low interests as an incentive for them to engage in entrepreneurship.

It is evidence showing that perceived behavioral control has a great correlation with entrepreneurial intention, consistent with many previous pieces of research. According to Trivedi (2016), scores of perceived behavioral control are found to have a positive relation with the intention to start a venture. Furthermore, Alonso-Galicia et al. (2015), Iglesias-Sánchez et al. (2016), Miranda et al. (2017), and Farooq et al. (2018) contributed to the fact that a significant and positive relationship between perceived behavioral control and the intention to have an enterprise established has existed. This may be because through the time studying at universities or exposure to entrepreneurship, undergraduates narrow down the gap between their perceived control and actual control. It is extremely essential to identify whether the planned behavior is feasible to successfully form a venture.

The influence of perceived education supports on the intention to become a venture founder was evaluated. The result implies that education support received from universities has a large and positive correlation with entrepreneurial intention. It simply refers to the fact that the necessary knowledge about entrepreneurship and skills and abilities related to entrepreneurship developed by studying at universities encourage undergraduates to confidently have the thought of being entrepreneurs in the future. In fact, students can learn the entrepreneurial knowledge, skills and improve their abilities through talk shows, workshops, competitions about entrepreneurship which are organized by clubs or faculties. In addition, doing class projects also helps students to enhance their comprehension about the business, such as how it works, how they overcome the problems. By being equipped with necessary elements, students would feel more empowered to have the intention to establish an enterprise. Moreover, perceived education support is found to have a significant impact on students' attitudes towards entrepreneurship. Through the activities undergraduates join at universities, their attitude towards entrepreneurship might be affected.

\section{Limitations and future direction}

On account of the lack of resources and time in research implementation, the study cannot avoid limitations. Firstly, the scope of the research is comparatively small. Only 312 valid responses of undergraduates in 3 particular universities were collected while there are 28 universities including public, private, and people-founded in HCMC that have fields related to economics. The undiversified sample and limited geographic accessibility capacity prevent the result to comprehensively illustrate the impact of university role on the entrepreneurial intention of the university students in the HCMC. Secondly, the findings were not deeply explained since the paper employed a quantitative method only. Some points in the paper could not exactly describe the real thoughts and beliefs of the undergraduates which should be involved in further research.

Since the research only focused on a narrow scope, the findings cannot reflect the intention to the start-up of undergraduates in HCMC as a whole. Therefore, it is essential to do research that covers more universities in HCMC with a bigger sample size that may accurately manifest the intention to pursue entrepreneurship of undergraduates in HCMC. Moreover, the environmental elements such as the status of the Vietnam economy and the government policies could be included in future research. 


\section{References}

Acs, Z. J., \& Szerb, L. (2009). The Global Entrepreneurship Index (GEINDEX). Foundations and Trends in Entrepreneurship, 5(5), 341-435. doi:10.1561/0300000027

Ajzen, I. (1985). From intentions to actions: A theory of planned behavior. In J. Kuhl \& J. Beckmann (Eds.), Action control: From cognition to behavior (SSSP Springer series in social psychology) (pp. 11-39). Berlin, Germany: Springer-Verlag Berlin Heidelberg.

Ajzen, I. (1991). The theory of planned behavior. Organizational Behavior and Human Decision Processes, 50(2), 179-211.

Ajzen, I. (2002). Perceived behavioral control, self-efficacy, locus of control, and the theory of planned behavior. Journal of Applied Social Psychology, 32(4), 665-683. doi:10.1111/j.1559-1816.2002.tb00236.x

Alonso-Galicia, P. E., Fernández-Pérez, V., Rodríguez-Ariza, L., \& Fuentes-Fuentes, M. D. M. (2015). Entrepreneurial cognitions in academia: Exploring gender differences. Journal of Managerial Psychology, 30(6), 630-644.

Al-Shammari, M., \& Waleed, R. (2018). Entrepreneurial intentions of private university students in the Kingdom of Bahrain. International Journal of Innovation Science, 10(1), 43-57. doi:10.1108/IJIS-06-2017-0058

Amésquita Cubillas, F., Morales, O., \& Rees, G. H. (2018). Understanding the intentions of informal entrepreneurs in Peru. Journal of Entrepreneurship in Emerging Economies, 10(3), 489-510.

Athayde, R. (2009). Measuring enterprise potential in young people. Entrepreneurship Theory and Practice, 33(2), 481-500.

Bagozzi, R. P., Baumgartner, J., \& Yi, Y. (1989). An investigation into the role of intentions as mediators of the attitude-behavior relationship. Journal of Economic Psychology, 10(1), 35-62. doi:10.1016/0167-4870(89)90056-1

Bandura, A. (1986). Social foundations of thought and action. Englewood Cliffs, NJ: Prentice Hall.

Bandura, A. (1993). Perceived self-efficacy in cognitive development and functioning. Educational Psychologist, 28(2), 117-148. doi:10.1207/s15326985ep2802_3

Bandura, A. (1997). Self-efficacy: The exercise of control. New York: W H Freeman/Times Books/ Henry Holt \& Co.

Bell, R. (2019). Predicting entrepreneurial intention across the university. Education + Training, 61(7/8), 815-831. doi:10.1108/ET-05-2018-0117

Bird, B. (1988). Implementing entrepreneurial ideas: The case for intention. Academy of Management Review, 13(3), 442-453. doi:10.2307/258091

Brandstätter, H. (2011). Personality aspects of entrepreneurship: A look at five meta-analyses. Personality and Individual Differences, 51(3), 222-230. doi:10.1016/j.paid.2010.07.007

Crant, J. M. (1996). The proactive personality scale as a predictor of entrepreneurial intentions. Journal of Small Business Management, 34(3), 42-49. 
De Noble, A. F., Jung, J., \& Ehrlich, S. B. (1999). Entrepreneurial self-efficacy: The development of a measure and its relationship to entrepreneurial action. In R. D. Reynolds, W. D. Bygrave, S. Manigart, C. M. Mason, G. D. Meyer, H. J. Sapienze, \& K. G. Shaver (Eds.), Frontiers of entrepreneurship research - 1999. Wellesley, MA: Babson College.

Farooq, M. S., Salam, M., ur Rehman, S., Fayolle, A., Jaafar, N., \& Ayupp, K. (2018). Impact of support from social network on entrepreneurial intention of fresh business graduates. Education + Training, 60(4), 335-353. doi:10.1108/ET-06-2017-0092

Ferreira, J. J., Raposo, M. L., Gouveia Rodrigues, R., Dinis, A., \& do Paço, A. (2012). A model of entrepreneurial intention: An application of the psychological and behavioral approaches. Journal of Small Business and Enterprise Development, 19(3), 424-440. doi:10.1108/14626001211250144

Fornell, C., \& Larcker, D. F. (1981). Structural equation models with unobservable variables and measurement error: Algebra and statistics. Journal of Marketing Research, 18(3), 382-388. doi: $10.2307 / 3150980$

Gelaidan, H. M., \& Abdullateef, A. O. (2017). Entrepreneurial intentions of business students in Malaysia: The role of self-confidence, educational and relation support. Journal of Small Business and Enterprise Development, 24(1), 54-67. doi:10.1108/JSBED-06-2016-0078

Gelard, P., \& Saleh, K. E. (2011). Impact of some contextual factors on entrepreneurial intention of university students. African Journal of Business Management, 5(26), 10707-10717. doi:10.5897/AJBM10.891

General Statistics Office of Vietnam. (2018). Vietnam youth unemployment rate. Retrieved from https://tradingeconomics.com/vietnam/youth-unemployment-rate

Gielnik, M. M., Zacher, H., \& Wang, M. (2018). Age in the entrepreneurial process: The role of future time perspective and prior entrepreneurial experience. Journal of Applied Psychology, 103(10), 1067-1085. doi:10.1037/ap10000322

Hair, J. F., Ringle, C. M., \& Sarstedt, M. (2011). PLS-SEM: Indeed a silver bullet. Journal of Marketing Theory and Practice, 19(2), 139-152.

Hair, J. F., Hult, G. M., Ringle, C. M., \& Sarstedt, M. (2013). A primer on Partial Least Squares Structural Equation Modeling (PLS-SEM). New York, NY: SAGE Publications, Inc.

Hair, J. F. J., Hult, G. T. M., Ringle, C. M., \& Sarstedt, M. (2017). A Primer on Partial Least Squares Structural Equation Modeling (PLS-SEM). Thousand Oaks, CA: Sage.

Hattab, H. W. (2014). Impact of entrepreneurship education on entrepreneurial intentions of university students in Egypt. The Journal of Entrepreneurship, 23(1), 1-18. doi:10.1177/0971355713513346

Henseler, J., Ringle, C. M., \& Sinkovics, R. R. (2009). The use of partial least square path modeling in international marketing. In R. R. Sinkovics \& P. N. Ghauri (Eds.), New challenges to international marketing (pp. 277-319). Bingley, UK: Emerald.

Heuer, A., \& Kolvereid, L. (2014). Education in entrepreneurship and the theory of planned behaviour. European Journal of Training and Development, 38(6), 506-523. doi:10.1108/EJTD-02-2013-0019 
Iglesias-Sánchez, P. P., Jambrino-Maldonado, C., Velasco, A. P., \& Kokash, H. (2016). Impact of entrepreneurship programmes on university students. Education + Training, 58(2), 209-228. doi:10.1108/ET-01-2015-0004

Kautonen, T., van Gelderen, M., \& Fink, M. (2015). Robustness of the theory of planned behavior in predicting entrepreneurial intentions and actions. Entrepreneurship Theory and Practice, 39(3), 655-674. doi:10.1111/etap.12056

Krueger, N. F., Reilly, M. D., \& Carsrud, A. L. (2000). Competing models of entrepreneurial intentions. Journal of Business Venturing, 15(5/6), 411-432. doi:10.1016/S08839026(98)00033-0

Lent, R. W., Brown, S. D., \& Hackett, G. (2000). Contextual supports and barriers to career choice: A social cognitive analysis. Journal of Counseling Psychology, 47(1), 36-49. doi:10.1037/0022-0167.47.1.36

Leutner, F., Ahmetoglu, G., Akhtar, R., \& Chamorro-Premuzic, T. (2014). The relationship between the entrepreneurial personality and the Big Five personality traits. Personality and Individual Differences, 63, 58-63. doi:10.1016/j.paid.2014.01.042

Liñán, F., \& Chen, Y. W. (2009). Development and cross-cultural application of a specific instrument to measure entrepreneurial intentions. Entrepreneurship Theory and Practice, 33(3), 593-617. doi:10.1111/j.1540-6520.2009.00318.x

Miranda, F. J., Chamorro-Mera, A., Rubio, S., \& Pérez-Mayo, J. (2017). Academic entrepreneurial intention: The role of gender. International Journal of Gender and Entrepreneurship, 9(1), 66-86. doi:10.1108/IJGE-10-2016-0037

Munir, H., Jianfeng, C., \& Ramzan, S. (2019). Personality traits and theory of planned behavior comparison of entrepreneurial intentions between an emerging economy and a developing country. International Journal of Entrepreneurial Behavior \& Research, 25(3), 554-580. doi:10.1108/IJEBR-05-2018-0336

Nasip, S., Amirul, S. R., Sondoh Jr., S. L., \& Tanakinjal, G. H. (2017). Psychological characteristics and entrepreneurial intention: A study among university students in North Borneo, Malaysia. Education + Training, 59(7/8), 825-840. doi:10.1108/ET-10-2015-0092

Parnell, J. A., Crandall, W. R., \& Menefee, M. (1995). Examining the impact of culture on entrepreneurial propensity: An empirical study of prospective American and Egyptian entrepreneurs. Academy of Entrepreneurship Journal, 2(1), 39-52.

Sahin, F., Karadag, H., \& Tuncer, B. (2019). Big five personality traits, entrepreneurial selfefficacy and entrepreneurial intention. International Journal of Entrepreneurial Behavior \& Research, 25(6), 1188-1211. doi:10.1108/IJEBR-07-2018-0466

Schlaegel, C., \& Koenig, M. (2014). Determinants of entrepreneurial intent: A meta-analytic test and integration of competing models. Entrepreneurship Theory and Practice, 38(2), 291332. doi:10.1111/etap.12087

Sesen, H. (2013). Personality or environment? A comprehensive study on the entrepreneurial intentions of university students. Education + Training, 55(7), 624-640. doi:10.1108/ET05-2012-0059 
Shah, N., \& Soomro, B. A. (2017). Investigating entrepreneurial intention among public sector university students of Pakistan. Education + Training, 59(7/8), 841-855. doi:10.1108/ET11-2016-0168

Shahab, Y., Chengang, Y., Arbizu, A. D., \& Haider, M. J. (2018). Entrepreneurial self-efficacy and intention: Do entrepreneurial creativity and education matter? International Journal of Entrepreneurial Behavior \& Research, 25(2), 259-280. doi:10.1108/IJEBR-12-2017-0522

Shinnar, R. S., Giacomin, O., \& Janssen, F. (2012). Entrepreneurial perceptions and intentions: The role of gender and culture. Entrepreneurship Theory and Practice, 36(3), 465-493. doi:10.1111/j.1540-6520.2012.00509.x

Sinha, T. N. (1996). Human factors in entrepreneurship effectiveness. Journal of Entrepreneurship, 5(1), 23-39. doi:10.1177/097135579600500102

Śledzik, K. (2013). Schumpeter's view on innovation and entrepreneurship. In S. Hittmar (Ed.), Management trends in theory and practice (pp. 89-95). Zilina, Slovakia: University Publishing House, University of Zilina. doi:10.2139/ssrn.2257783

Thompson, E. R. (2009). Individual entrepreneurial intent: Construct clarification and development of an internationally reliable metric. Entrepreneurship: Theory and Practice, 33(3), 669-694. doi:10.1111/j.1540-6520.2009.00321.x

Trivedi, R. (2016). Does university play significant role in shaping entrepreneurial intention? A cross-country comparative analysis. Journal of Small Business and Enterprise Development, 23(3), 790-811. doi:10.1108/JSBED-10-2015-0149

Turker, D., \& Sonmez Selcuk, S. (2009). Which factors affect entrepreneurial intention of university students? Journal of European Industrial Training, 33(2), 142-159. doi:10.1108/03090590910939049

United Nations Conference on Trade and Development. (2008). Investment policy review of Vietnam - UNCTAD. Retrieved July 13, 2019, from https://unctad.org/en/Docs/td442_en.pdf

World Bank. (2016). Ease of doing business in Vietnam. Retrieved July 14, 2019, from https://tradingeconomics.com/vietnam/ease-of-doing-business

Zhang, P., \& Cain, K. W. (2017). Reassessing the link between risk aversion and entrepreneurial intention. International Journal of Entrepreneurial Behavior \& Research, 23(5), 793-811. 